Review Article

\title{
Delirium: Assessment and Management - A Review
}

\author{
Nitin Kumar', Prerna Kukreti \\ ${ }^{1}$ Junior Resident, ${ }^{2}$ Associate Professor, Department of Psychiatry and Drug De-Addiction Centre, Lady Hardinge Medical \\ College, New Delhi, India.
}

DOI: https://doi.org/10.24321/2581.5822.202010

\section{I $\quad \mathbf{N} \quad \mathbf{F} \quad \mathbf{O}$}

\section{Corresponding Author:}

Nitin Kumar, Department of Psychiatry and Drug De-Addiction Centre, Lady Hardinge Medical College, New Delhi, India.

E-mail Id:

singhnitinkumar12@gmail.com

Orcid Id:

https://orcid.org/0000-0002-6141-136X

How to cite this article:

Kumar N, Kukreti P. Delirium: Assessment and Management- A Review. J Adv Res Psychol

Psychother 2020; 3(3\&4): 21-27.

Date of Submission: 2020-06-04

Date of Acceptance: 2020-12-12

\section{$\begin{array}{llllllll}\mathbf{A} & \mathbf{B} & \mathbf{S} & \mathbf{T} & \mathbf{R} & \mathbf{A} & \mathbf{C} & \mathbf{T}\end{array}$}

Delirium is described as a syndrome characterized by disturbed consciousness, cognitive function or perception, which is acute in onset and has fluctuating course. This article serves to provide a brief review of this condition with respect to diagnostic classification, epidemiology, etiopathogenesis and types. Furthermore, a focused discussion on its assessment and management in routine clinical practice has been documented.

Keywords: Delirium, Acute Confusional State, Assessment, Management

\section{Introduction}

Toxic psychosis, ICU psychosis, organic brain syndrome, encephalopathy, encephalitis, acute organic state, acute organic psychosis, acute confusional state, acute brain failure are few names that have been provided in the literature for delirium.

As per NICE (2010), ${ }^{1}$ delirium has been defined as "A common clinical syndrome characterized by disturbed consciousness, cognitive function or perception, which has an acute onset and fluctuating course." DSM- $5(2013)^{2}$ describes delirium as "Disturbance of attention or awareness that is accompanied by a change in baseline cognition that cannot be better explained by a pre-existing or evolving neurocognitive disorder."

ICD-11 states "Delirium is characterized by disturbed attention (i.e., reduced ability to direct, focus, sustain, and shift attention) and awareness (i.e., reduced orientation to the environment) that develops over a short period of time and tends to fluctuate during the course of a day, accompanied by other cognitive impairment such as memory deficit, disorientation, or impairment in language, visuospatial ability, or perception." ${ }^{3}$

Among these entire definitions disturbance in attention and awareness, acute onset and fluctuating course seem prominent and common features.

\section{Clinical Features and Diagnostic Critera}

As there is no recognized physiologic measure, diagnosis of delirium is made on the basis of history, physical examination, mental status examination and enquiring about onset, course of illness from family members as patient is not able to give all these information. ${ }^{4}$

Clinical history may indicate toward abrupt/ acute onset, fluctuating severity over 24 hours with disturbed sleep 
wake cycle in which mainly sleep is fragmented, with sleeplessness in night with characteristic reversal of sleep wake cycle, ${ }^{5}$ diffuse cognitive deficits mainly attention, orientation, memory, visuo-spatial ability, ${ }^{6}$ with disturbance in psychomotor behaviour i.e. hyperactive, hypoactive or both, ${ }^{7,6}$ hallucinations (more commonly visual) and delusions (not well formed, paranoid). ${ }^{8}$ Language impairment and disorganized thinking may be seen. ${ }^{8,9}$

ICD $10,{ }^{10}$ ICD $11^{3}$ and DSM $5^{2}$ have used all these features in their respective guidelines, detailed in Table 1.

Table I.Diagnostic criteria for delirium in ICD I0, ICD I I, DSM 5

\begin{tabular}{|c|c|c|}
\hline ICD & 13 & SM 52 \\
\hline $\begin{array}{l}\text { For a definite } \\
\text { diagnosis, symptoms, } \\
\text { mild or severe, } \\
\text { should be present } \\
\text { in each one of the } \\
\text { following areas: } \\
\text { - Impairment of } \\
\text { consciousness } \\
\text { and attention } \\
\text { - Global } \\
\text { disturbance of } \\
\text { cognition } \\
\text { - Psychomotor } \\
\text { disturbances } \\
\text { - Disturbance of } \\
\text { the sleep-wake } \\
\text { cycle } \\
\text { Emotional } \\
\text { disturbances }\end{array}$ & $\begin{array}{l}\text { All definition Criteria should } \\
\text { meet } \\
\text { "Delirium is characterized } \\
\text { by disturbed attention (i.e., } \\
\text { reduced ability to direct, } \\
\text { focus, sustain, and shift } \\
\text { attention) and awareness } \\
\text { (i.e., reduced orientation } \\
\text { to the environment) that } \\
\text { develops over a short } \\
\text { period of time and tends to } \\
\text { fluctuate during the course } \\
\text { of a day, accompanied by } \\
\text { other cognitive impairment } \\
\text { such as memory deficit, } \\
\text { disorientation, or } \\
\text { impairment in language, } \\
\text { visuospatial ability, or } \\
\text { perception" }\end{array}$ & $\begin{array}{l}\text { - Disturbance in attention (i.e., reduced ability to direct, } \\
\text { focus, sustain and shift attention) and awareness (reduced } \\
\text { orientation to the environment) } \\
\text { - The disturbance develops over a short period of time } \\
\text { (usually hours to a few days), represents an acute change } \\
\text { from baseline attention and awareness, and tends to } \\
\text { fluctuate in severity during the course of a day } \\
\text { - An additional disturbance in cognition (e.g. memory deficit, } \\
\text { disorientation, language, visuospatial ability, or perception) } \\
\text { The disturbances in Criteria A and C are not better } \\
\text { explained by a pre-existing, established or evolving } \\
\text { Neurocognitive disorder and do not occur in the context of } \\
\text { a severely reduced level of arousal such as coma } \\
\text { There is evidence from the history, physical examination } \\
\text { or laboratory findings that the disturbance is a direct } \\
\text { physiological consequence of another medical condition, } \\
\text { substance intoxication or withdrawal (i.e. due to a drug of } \\
\text { abuse or to a medication), or exposure to a toxin, or is due } \\
\text { to multiple etiologies }\end{array}$ \\
\hline
\end{tabular}

Table 2.Predisposing and Precipitating Factors of Delirium ${ }^{14,16,17}$

\begin{tabular}{|c|c|c|}
\hline \multicolumn{2}{|c|}{ Predisposing Factors } & \multirow{3}{*}{$\begin{array}{ll} & \text { Precipitating Factors } \\
\text { - } & \text { Immobility } \\
\text { - } & \text { Dehydration } \\
\text { - } & \text { Use of bladder catheter } \\
\text { - } & \text { Use of physical } \\
& \text { restrained } \\
\text { - } & \text { Hypoxia } \\
\text { - } & \text { Intercurrent illness } \\
\text { - } & \text { Malnutrition } \\
\text { - } & \text { Change of Environment }\end{array}$} \\
\hline $\begin{array}{ll} & \text { Patient's Factors } \\
\text { - } & \text { Old Age } \\
\text { - } & \text { Male } \\
\text { - } & \text { Dementia } \\
\text { - } & \text { Previous delirium }\end{array}$ & $\begin{array}{l}\text { Medical Causes } \\
\text { - Infections } \\
\text { - Severity of illness } \\
\text { - } \quad \text { Chronic renal or hepatic disease } \\
\text { - } \quad \text { Stroke }\end{array}$ & \\
\hline 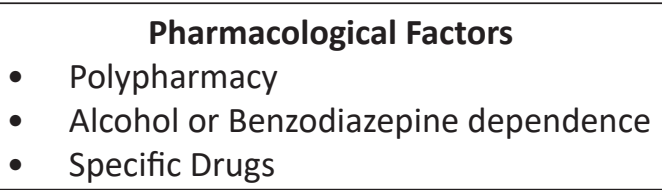 & $\begin{array}{l}\text { - } \quad \text { Neurological disease } \\
\text { - } \quad \text { Fractures or trauma } \\
\text { - Hypotension and Hypo perfusion } \\
\text { - Hypoxia or anoxia }\end{array}$ & \\
\hline $\begin{array}{l}\text { Perioperative } \\
\text { - } \quad \text { Course of postoperative period } \\
\text { - } \quad \text { Type of operation (for example, hip } \\
\text { replacement) } \\
\text { - } \quad \text { Emergency operation } \\
\text { - } \quad \text { Duration of operation }\end{array}$ & $\begin{array}{l}\text { - Malnutrition and nutritional } \\
\text { deficiencies } \\
\text { - } \quad \text { cute vascular problems (e.g., } \\
\text { myocardial infarction, pulmonary } \\
\text { embolism) } \\
\text { - Endocrinopathies }\end{array}$ & \multirow{2}{*}{$\begin{array}{ll} & \text { Medicines (High Risk) } \\
\text { - } & \text { Benzodiazepines } \\
\text { - } & \text { Opioid analgesics } \\
\text { - } & \text { Antiparkinsonian agents } \\
\text { - } & \text { Antidepressants } \\
\text { - } & \text { Centrally acting agents } \\
\text { - } & \text { Corticosteroids } \\
\text { - } & \text { Lithium }\end{array}$} \\
\hline $\begin{array}{l}\text { Environmental Factors } \\
\text { - } \quad \text { Hypothermia/Hyperthermia } \\
\text { - } \quad \text { Visual Impairment } \\
\text { - } \quad \text { Hearing Impairment } \\
\text { - } \quad \text { Impaired ADL and Mobility }\end{array}$ & $\begin{array}{l}\text { Water and Metabolic derangements } \\
\text { - Hypo- or hyper-glycemia } \\
\text { - } \text { Hyponatremia } \\
\text { - } \text { Hypokalemia } \\
\text { - } \quad \text { Dehydration } \\
\text { - } \quad \text { Hypoalbuminaemia } \\
\text { - } \quad \text { Hypocalcaemia } \\
\end{array}$ & \\
\hline
\end{tabular}




\section{Epidemiology}

Delirium is most common in mechanically ventilated patients in the ICU with prevalence up to $80 \%{ }^{11}$ giving it the name "ICU Psychosis." Among general hospital adult inpatients prevalence of delirium is 17.6 to $19.6 \% .{ }^{12} \mathrm{Among}$ all admissions to ICU and in advanced cancer and palliative care prevalence of delirium is $\geq 50 \% .{ }^{13}$ Likewise, prevalence among patients presenting to emergency departments is up to $10 \%$, in all admissions to general hospitals $10 \%$ to $30 \%$, among inpatients in general medical settings $\geq 33 \%$, among hip fracture patients $66 \%$, in old people and nursing homes, delirium is found in about $60 \%$ people. ${ }^{14}$

\section{Etiology}

Delirium can be multifactorial. Practically any physiological derangement can cause delirium in a susceptible individual. In a prospective study of delirium in elderly patients, Francis and colleagues identified five leading causes of delirium: a) Fluid/ Electrolyte disturbance b) Infection c) Medication toxicity d) Metabolic derangement e) Sensory and environmental disturbance. ${ }^{15}$

\section{Neurobiology}

Several hypotheses have been given to explain several clinical features and Neurobiological basis of delirium prominent ones are neurotransmitter hypothesis, neuroinflammatory hypothesis, neuronal ageing hypothesis, oxidative stress hypothesis, neuroendocrine hypothesis, circadian rhythm dysregulation hypothesis and others.

- Neurotransmitter hypothesis: Involvement of Cholinergic \& dopaminergic pathways, glutamate, serotonin and GABA-ergic pathways. ${ }^{18}$

- Neuroinflammatory hypothesis: Activation of peripheral immune system, release of pro-inflammatory cytokines (IL-6, 8, 10, TNF) by the brain parenchyma, neopterin, S100 beta protein. ${ }^{19,20}$

- Neuronal ageing hypothesis: Age related cerebral atrophy and neuronal loss, changes in neuro-transmitter systems, reduction of the blood brain flow as well as regional blood flow, reduction in the cerebral metabolic rate of oxygen and decreased oxygen supply and thus reduced redox activity. ${ }^{21-23}$

- Oxidative stress hypothesis: increase in consumption of oxygen or reduced availability of oxygen and altered cerebral metabolism and thus a state of oxidative stress. ${ }^{24}$

- Neuroendocrine hypothesis: activation of the hypo-thalamic-pituitary system, malfunction of the glucocorticoid receptors in the hippocampus and limbic system, which regulates the negative feedback on the HPA axis. ${ }^{25,26}$

- Circadian rhythm dysregulation hypothesis: Desynchronization of circadian rhythm including sleeplessness, reversal of sleep-wake cycle, and fragmentation of sleep. ${ }^{27}$

- Other etiological theories- Neural dysconnectivity hypothesis, Orexinergic neurons in the peri-fornical nucleus, involvement of vitamin B complex, folate, lipids and anti-oxidants. ${ }^{28,29}$

In current understanding delirium is thought to be cumulative effect of these entire hypothesis altogether.

\section{Subtypes}

Delirium was first divided by Liptzin \& Levkoff, ${ }^{30}$ depending upon the motor activity into three major types: hyperactive, hypoactive and mixed. Hyperactive delirium comprising of patients with restlessness, wandering behaviour, increased psychomotor activity, loss of control of activity, increased speech, aggression uncooperation, hyper alert, increased startle response, hallucinations. Hypoactive delirium characterized by apathy, listlessness, decreased activity levels, decreased speed, social withdrawal, hypo-alert, hypesomnolence. Mixed delirium has features of both and is the most common of all three varieties.

\section{Assessment}

A comprehensive assessment of delirium must include following components:

- Clinical History: Proper history should be elicited from available informants regarding all clinical features as previously mentioned in this article.

- General and Systemic Examination: Complete general and systemic examination should be done keeping in mind all possible etiologies as motioned in the Table 2

- Rating Scales

- Lab workup

\section{Rating Scales}

Several Scales have been developed for assessment of level of consciousness, screening, diagnosis, severity and aetiology of delirium.

- To see whether the patient is arousable and in a state to be assessed for delirium

0

- Scales for screening

- MMSE (Mini Mental State Examination)

- CAM ICU/ CAM

- NEECHAM confusion scale

- Delirium Observation screening scale

- Intensive care delirium screening checklist

- Global attentiveness rating

- Diagnostic scales

- Delirium symptom interview

- Saskatoon delirium checklist

- Delirium rating scale 
0

- Scale to assess severity of delirium

- Delirium Rating Scale

Delirium-O-Meter

Delirium Severity Scale

- Aetiology

- Delirium aetiology checklist

\section{Lab linvestigations}

Lab investigation for delirium includes routine investigation and level two investigations which should be done if indications are present. Routine investigations include full blood count, CRP, urea and electrolytes, glucose, calcium, LFTs, KFTs and ECG. If indicated, chest X-ray, urinalysis, blood cultures, pulse oximetry, arterial blood gases, vitamin B12 and folate, thyroid function tests, specific cultures (e.g. sputum, urine), CT of the head, lumbar puncture, EEG can also be done. ${ }^{14,31}$

EEG in delirium shows generalized slowing except for delirium tremens. Slow posterior rhythms, diffuse delta/ theta waves, poor background rhythm organization, loss of reactivity ${ }^{32}$ are characteristic of delirium. However, EEG is not recommended for making diagnosis. 6 Evoked potentials are also abnormal. ${ }^{33}$

\section{Differential Diagnosis}

About $1 / 3$ to $2 / 3$ cases are missed across range of therapeutic settings and specialists. 34 Causes cited for the same are non-recognition, fluctuating symptom..$^{35,36}$ Diagnosis is more likely to be missed or misdiagnosed in elderly, patients with sensory impairments, patients with pre-existing dementia, delirium of hypoactive type ${ }^{37}$ or due to lack of sensitivity of screening instruments. ${ }^{38}$ Delirium is often confused with dementia, depression, and schizophrenia/psychosis superficially and therefore must be differentiated from the same. Differential diagnosis details are given in Table 3.

\section{Management}

Management of Delirium should be done by treatment of all possible underlying causes and includes:

1. Prevention

2. Non Pharmacological Management

3. Pharmacological Management

\section{Prevention}

NICE in 2010,1 provided detailed guidelines about prevention of delirium, it is summarized as follows:

- Avoid polypharmacy: Carry out a medication review: both the type and number of medications

Table 3.Differential diagnosis of Delirium ${ }^{6}$

\begin{tabular}{|c|c|c|c|c|}
\hline & Delirium & Dementia & Depression & Schizophrenia \\
\hline Clinical Picture & $\begin{array}{l}\text { Fluctuating levels } \\
\text { of consciousness, } \\
\text { decreased attention }\end{array}$ & $\begin{array}{l}\text { Memory impairment } \\
\text { with normal level of } \\
\text { consciousness }\end{array}$ & $\begin{array}{l}\text { Sadness of mood, loss } \\
\text { of pleasure and interest } \\
\text { in usual activities }\end{array}$ & $\begin{array}{c}\text { Hallucinations, } \\
\text { delusions, disorganised } \\
\text { behaviour }\end{array}$ \\
\hline Onset & Acute & Insidious & Variable & Variable \\
\hline Course & $\begin{array}{c}\text { Fluctuating; short with } \\
\text { diurnal variations }\end{array}$ & $\begin{array}{c}\text { Steadily progressive } \\
\text { and chronic }\end{array}$ & $\begin{array}{l}\text { over months, morning } \\
\text { worsening }\end{array}$ & Variable \\
\hline $\begin{array}{l}\text { Consciousness } \\
\& \text { Orientation }\end{array}$ & Clouded; Disoriented & $\begin{array}{l}\text { Clear until late } \\
\text { stages }\end{array}$ & Generally Unimpaired & $\begin{array}{c}\text { Unimpaired but may } \\
\text { be perplexed in acute } \\
\text { stage }\end{array}$ \\
\hline Thinking & Disorganized & Impaired judgment & Intact & disorganized \\
\hline $\begin{array}{l}\text { Attention and } \\
\text { Memory }\end{array}$ & $\begin{array}{c}\text { Poor short term } \\
\text { memory; inattention }\end{array}$ & $\begin{array}{l}\text { Poor short term } \\
\text { memory without } \\
\text { marked inattention }\end{array}$ & $\begin{array}{l}\text { Poor attention but } \\
\text { memory intact }\end{array}$ & $\begin{array}{l}\text { Poor attention but } \\
\text { memory intact }\end{array}$ \\
\hline $\begin{array}{l}\text { Psychomotor } \\
\text { Activity }\end{array}$ & $\begin{array}{l}\text { Depending on subtype; } \\
\text { generally increased }\end{array}$ & Normal & Reduced & Variable \\
\hline $\begin{array}{c}\text { Sleep Wake } \\
\text { Cycle }\end{array}$ & $\begin{array}{l}\text { Disturbed/reversed } \\
\text { sleep-wake cycle }\end{array}$ & $\begin{array}{l}\text { Disturbed; may be } \\
\text { fragmented }\end{array}$ & $\begin{array}{l}\text { Early morning } \\
\text { awakening or } \\
\text { Hypersomnia }\end{array}$ & Poor sleep \\
\hline EEG & $\begin{array}{l}\text { Abnormal in } 80-90 \% ; \\
\text { Generalized Diffuse } \\
\text { slowing in } 80 \%\end{array}$ & $\begin{array}{l}\text { Abnormal in } 80-90 \% ; \\
\text { Generalized Diffuse } \\
\text { slowing in } 80 \%\end{array}$ & Generally Normal & Generally normal \\
\hline
\end{tabular}


- Use Anticholinergic, Opioid and sedatives carefully

- Maintain hydration status

- Train caregivers and nursing staff to recognize delirium

- Regular assessment especially in elderly

- Avoid moving people within and between wards or rooms unless absolutely necessary

- Address immobility or limited mobility

- Address pain by: looking for non-verbal signs of pain, starting and reviewing appropriate pain management

- Address poor nutrition, if people have dentures ensuring they fit properly

- Address sensory impairment by: resolving any reversible cause (e.g. impacted ear wax), hearing and visual aids.

- Promote good sleep patterns and sleep hygiene by:

- avoid procedures during sleeping hours, if possible - scheduling medication rounds to avoid disturbing sleep - Reducing noise to a minimum during sleep periods

\section{Non Pharmacologiacl Management}

Non Pharmacological management is as important as pharmacological management in patients of Delirium as it can help in reducing Polypharmacy which is again an individual etiological cause of delirium. Non pharmacological management includes providing support and orientation, providing an unambiguous environment and maintaining competence. ${ }^{16}$

\section{Providing Support and Orientation}

- Short and clear communication with the patient; frequent reorientation especially about family members and treating team

- Place clock, calendar and days schedule with the patient

- Objects from home should be brought to make hospital familiar

- Use TV or Radio to help maintain contact with the outside world

- Involve attendants to give a feeling of safety

Providing an Unambiguous Environment

- Remove unnecessary objects from the room

- Minimize unnecessary sensory stimulation

- Maintain adequate lighting even In night to avoid a perceptual abnormality

- Keep room temperature I comfortable range

\section{Maintaining Competence}

- $\quad$ Correct any possible sensory impairments using hearing or visual aids

- Encourage patients involvement In treatment and promote self-care

- Maintain possible activity levels

- Avoid intervention during sleep hours

\section{Pharmacological Management}

Pharmacological management is required is delirium only if it is due to drug withdrawal (alcohol/ benzodiazepines) or when there is physical aggression causing harm to patient or others. Mainly antipsychotics ad benzodiazepines are used, where benzodiazepines are used for alcohol/ benzodiazepine withdrawal delirium.

\section{Typical Antipsychotics}

Among typical antipsychotics most evidence is for Haloperidol. As per NICE 2010, ${ }^{1}$ Haloperidol for shortterm (usually for 1 week or less) can be given, to start at the lowest clinically appropriate dose and titrate cautiously according to symptoms. ${ }^{1}$ Similarly, short term Haloperidol $2.5 \mathrm{mg}$ to $10 \mathrm{mg}$ oral/ IM per day has been recommended by other studies. ${ }^{39-41}$ It has certain advantages such as, can be given orally or $\mathrm{I} / \mathrm{M},{ }^{42}$ lesser propensity to cause metabolic side effects, reduces overall mortality and can be helpful in paediatric delirium. ${ }^{43}$ However, it should be used with precaution in presence of ECG changes. ${ }^{44}$

\section{Atypical Antipsychotics}

Atypical Antipsychotics can also be used, however, evidence is still not robust and agents like Clozapine may even cause delirium. Among atypical maximum evidence is for Risperidone, Olanzapine, with emerging evidence on Quetiapine. ${ }^{6}$ Second-generation antipsychotics, such as Risperidone, Clozapine, Olanzapine, Quetiapine, Ziprasidone, and Aripiprazole, may be considered. But these agents are associated with increased mortality in patient of dementia.

For patients with Parkinson's disease and delirium who require antipsychotic medications, Clozapine or Quetiapine have some support in the literature.

\section{Other Psychotropics}

Other molecules that have also been used are Donezepil, Rivastagmine, Melatonin and Sodium Valproate.

\section{Modified Electroconvulsive Therapy}

It has been used as a last resort for delirious patients with severe agitation who are not responsive to pharmacotherapy.

\section{Delirium Tremens}

When delirium is associated with sedative-hypnotic and alcohol withdrawal, Benzodiazepines can be given as Symptom triggered, Front loading and Fixed dose reduction regimen..$^{45}$ In symptom triggered $20-30$ mg Chlordiazepoxide stat, then as needed hourly based on Symptoms. In frontloading bolus dose of $10 \mathrm{mg}$ IV Diazepam equivalent every 5-20 minutes until (a) light sedation (drowsy but verbally responsive) is achieved (b) CIWA-Ar scores are $<10$, Then 
5-20 mg every hour as maintenance can be given. 45 In Fixed dose reduction dose of Benzodiazepine can be calculated if for example, 20 Units consumed/day, then Dose of Chlordiazepoxide given is $20 \mathrm{mg}$ QID which is gradually tapered off. ${ }^{46}$ In delirium tremens, Prophylactic Thiamine minimum of $300 \mathrm{mg}$ daily for 5 days, and then followed by Oral Thiamine in assisted withdrawal.46 In literature up to 300 to $1500 \mathrm{mg} /$ day Thiamine has been suggested in various articles. ${ }^{47,48}$ However, there is lack of consensus with respect to exact dosage of Thiamine required in patients presenting with Delirium tremens and is a potential area of research.

\section{Conclusion}

Delirium is an acute confusional state which affects the global outcome and prognosis of severely ill patients. It substantially surges health-care utilization and costs; therefore, prevention, early recognition and effective treatment of delirium are indispensable in this condition. Swift screening and proactive management is the cornerstone of reducing the incident and prevalence. Along with pharmacological, non-pharmacological interventions are imperative.

\section{Conflict of Interest: None}

\section{References}

1. National Institute for Health and Clinical Excellence. Delirium: diagnosis, prevention and management. NICE; 2010.

2. Diagnostic and statistical manual of mental disorders: DSM-5. 5th ed. Washington, D.C. American Psychiatric Association; 2013.

3. ICD-11 for Mortality and Morbidity Statistics. Geneva: World Health Organization; 2019.

4. Neufeld KJ, Thomas C. Delirium: definition, epidemiology and diagnosis. Journal of Clinical Neurophysiology 2013; 30(5): 438-442.

5. American Psychiatric Association: Practice guideline for the treatment of patients with delirium. Am J Psychiatry 2000; 156(5): 1-39.

6. Meagher D, Trzepacz PT: Phenomenological distinctions needed in DSM-V: delirium, subsyndromal delirium, and dementias. The Journal of neuropsychiatry and clinical neurosciences 2007; 19(4): 468-470.

7. Lipowski ZJ. Delirium: acute confusional states. Delirium after surgery, burns, and childbirth 1990; 442-478.

8. Trzepacz PT, Mittal D, Torres R, Kanary K, Norton J, Jimerson N. Validation of the Delirium Rating Scalerevised-98: comparison with the delirium rating scale and the cognitive test for delirium. The Journal of neuropsychiatry and clinical neurosciences 2001; 13(2): 229-242.

9. Rockwood K. The occurrence and duration of symptoms in elderly patients with delirium. Journal of Gerontology 1993; 48(4): 61-62.

10. ICD-10 Classifications of Mental and Behavioural Disorder: Clinical Descriptions and Diagnostic Guidelines. Geneva: World Health Organization; 1992.

11. Riker RR, Shehabi Y, Bokesch PM, Ceraso D, Wisemandle W, Koura F. Dexmedetomidine vs midazolam for sedation of critically ill patients: a randomized trial. JAMA 2009; 301(5): 489-499.

12. Ryan DJ, O’Regan NA, Caoimh RÓ, Clare J, O’Connor $\mathrm{M}$, Leonard $\mathrm{M}$ et al. Delirium in an adult acute hospital population: predictors, prevalence and detection. BMJ open 2013; 1:3.

13. Lindesay J, Rockwood K, Macdonald A, editors. Delirium in old age. OUP Oxford; 2002.

14. Siddiqi N, House AO, Holmes JD: Occurrence and outcome of delirium in medical in-patients: a systematic literature review. Age and ageing 2006; 35(4): 350-364.

15. Francis J, Martin D, Kapoor WN: A prospective study of delirium in hospitalized elderly. JAMA 1990; 263(8): 1097-101.

16. Meagher DJ: Delirium: optimising management. BMJ 2001; 322(7279): 144-149.

17. Bowen JD, Larson EB: Drug-induced cognitive impairment. Drugs \& aging 1993; 3(4): 349-357.

18. Trzepacz PT. Is there a final common neural pathway in delirium? Focus on acetylcholine and dopamine. InSeminars in clinical neuropsychiatry 2000; 5(2): 132148.

19. Cerejeira J, Lagarto L, Mukaetova-Ladinska EB. The immunology of delirium. Neuroimmunomodulation 2014; 21(2-3): 72-78.

20. Hall RJ, Ferguson KJ, Andrews M, Green AJ, White TO, Armstrong IR et al. Delirium and cerebrospinal fluid S100B in hip fracture patients: a preliminary study. The American Journal of Geriatric Psychiatry 2013; 21(12): 1239-1243

21. Juraska JM, Lowry NC. Neuroanatomical changes associated with cognitive aging. In Behavioral Neurobiology of Aging 2011; 137-162.

22. Lee $\mathrm{KH}, \mathrm{Ha} Y \mathrm{YC}$, Lee $\mathrm{YK}$, Kang $\mathrm{H}$, Koo KH. Frequency, risk factors, and prognosis of prolonged delirium in elderly patients after hip fracture surgery. Clinical Orthopaedics and Related Research 2011; 469(9): 2612-2620.

23. Maldonado JR. Neuropathogenesis of delirium: review of current etiologic theories and common pathways. The American Journal of Geriatric Psychiatry 2013; 21(12): 1190-222.

24. Schoen J, Meyerrose J, Paarmann H, Heringlake $M$, Hueppe M, Berger KU. Preoperative regional cerebral oxygen saturation is a predictor of postoperative delirium in on-pump cardiac surgery patients: a prospective observational trial. Critical care 2011; 
15(5): R218

25. Kazmierski J, Banys A, Latek J, Bourke J, Jaszewski R. Cortisol levels and neuropsychiatric diagnosis as markers of postoperative delirium: a prospective cohort study. Critical Care 2013; 17(2): R38.

26. Pearson A, de Vries A, Middleton SD, Gillies F, White TO, Armstrong IR et al. Cerebrospinal fluid cortisol levels are higher in patients with delirium versus controls. $B M C$ research notes 2010; 3(1): 33.

27. Tranah GJ, Blackwell T, Stone KL, Ancoli-Israel S, Paudel $\mathrm{ML}$, Ensrud KE et al. Circadian activity rhythms and risk of incident dementia and mild cognitive impairment in older women. Annals of neurology 2011; 70(5): 722-732.

28. Sanford AM, Flaherty JH. Do nutrients play a role in delirium? Current Opinion in Clinical Nutrition \& Metabolic Care 2014; 17(1): 45-50.

29. Choi SH, Lee H, Chung TS, Park KM, Jung YC, Kim SI et al. Neural network functional connectivity during and after an episode of delirium. American Journal of Psychiatry 2012; 169(5): 498-507.

30. Liptzin B, Levkoff SE. An empirical study of delirium subtypes. Br J Psychiatry 1992; 161: 843-5.

31. Trzepacz PT, Meagher DJ, Wise MG. Neuropsychiatric Aspects of Delirium. 2004.

32. Jacobson S, Jerrier HE. EEG in delirium. InSeminars in clinical neuropsychiatry 2000; 5(2): 86-92.

33. Trzepacz PT, Sclabassi RJ, Van Thiel DH. Delirium: a subcortical phenomenon? The Journal of neuropsychiatry and clinical neurosciences 1989; 1(3): 283-290.

34. Johnson JC, Kerse NM, Gottlieb G, Wanich C, Sullivan $E$, Chen K. Prospective versus retrospective methods of identifying patients with delirium. Journal of the American Geriatrics Society 1992; 40(4): 316-319.

35. Kakuma R, Du Fort GG, Arsenault L, Perrault A, Platt RW, Monette J et al. Delirium in older emergency department patients discharged home: effect on survival. Journal of the American Geriatrics Society 2003; 51(4): 443-450.

36. Hustey FM, Meldon SW, Smith MD, Lex CK. The effect of mental status screening on the care of elderly emergency department patients. Annals of emergency medicine 2003; 41(5): 678-684.

37. Inouye SK, Foreman MD, Mion LC, Katz KH, Cooney Jr LM. Nurses' recognition of delirium and its symptoms: comparison of nurse and researcher ratings. Archives of internal medicine 2001; 161(20): 2467-2473.

38. Gagnon P, Allard P, Mâsse B, DeSerres M. Delirium in terminal cancer: a prospective study using daily screening, early diagnosis, and continuous monitoring. Journal of pain and symptom management 2000; 19(6): 412-426.
39. Hua H, Deng W, Yang H, Liu Y. Olanzapine and haloperidol for senile delirium: a randomized controlled observation. Chinese Journal of Tissue Engineering Research 2006; 10(42): 188-190.

40. Choi HG, Park BS, Lee HJ, Choi JS, Jho KH, Shin YM. A Prospective and Open-Label Trial of Quetiapine and Haloperidol in the Treatment of Delirium. Korean Journal of Psychosomatic Medicine 2005; 13(2): 85-94.

41. Miyaji S, Yamamoto K, Hoshino S, Yamamoto H, Sakai Y, Miyaoka H. Comparison of the risk of adverse events between risperidone and haloperidol in delirium patients. Psychiatry and clinical neurosciences 2007; 61(3): 275-282.

42. Sanders KM, Stern TA. Management of delirium associated with use of the intra-aortic balloon pump. American Journal of Critical Care 1993; 2(5): 371-377.

43. Leentjens AF, Schieveld JN, Leonard M, Lousberg $R$, Verhey FR, Meagher DJ. A comparison of the phenomenology of pediatric, adult, and geriatric delirium. Journal of Psychosomatic Research 2008; 64(2): 219-223.

44. Practice guideline for the treatment of patients with delirium. American Psychiatric Association. Am J Psychiatry 1999; 156(5 Suppl): 1-20. PMID: 10327941.

45. Kattimani S, Bharadwaj B. Clinical management of alcohol withdrawal: A systematic review. Industrial psychiatry journal 2013; 22(2): 100.

46. Addictions and substance misuse. In: David MT, Thomas REB, Allan HY, editors. The Maudsley Prescribing Guidelines in Psychiatry. $13^{\text {th }}$ ed. West Sussex, Wiley Blackwell; 2019.

47. Achunine G, Taylor DM. Drugs for alcohol dependence. Medicine 2012; 40(12): 686-7.

48. Brown LM, Rowe AE, Ryle PR, Majumdar SK, Jones D, Thomson AD et al. Efficacy of vitamin supplementation in chronic alcoholics undergoing detoxification. Alcohol and Alcoholism 1983; 18(2): 157-166. 